\title{
In vitro evaluation of stearylamine cationic nanoemulsions for improved ocular drug delivery
}

BISERA JURIŠIĆ DUKOVSKI

ANA BRAČKO

MARIJA ŠARE

IVAN PEPIĆ

JASMINA LOVRIĆ*

University of Zagreb Faculty of Pharmacy and Biochemistry, Department of Pharmaceutical Technology, HR-10000 Zagreb, Croatia
Accepted July 10, 2019

Published online September 9, 2019

\begin{abstract}
Oil-in-water nanoemulsions (NEs) represent one of the formulation approaches to improve eye-related bioavailability of lipophilic drugs. The potential of cationic NEs is pronounced due to the electrostatic interaction of positively charged droplets with negatively charged mucins present in the tear film, providing prolonged formulation residence at the ocular surface. The aim of this study was to develop a cationic ophthalmic NE with cationic lipid stearylamine (SA) as a carrier of a positive charge. The addition of a nonionic surfactant provided the dual electro-steric stabilization of NEs and enabled tuning of SA concentration to achieve an optimal balance between its interaction with mucins and biocompatibility. Physicochemical characterization, stability profile, in vitro mucoadhesion study and biocompatibility study employing 3D HCE-T cell-based model of corneal epithelium pointed out the NE with $0.05 \%(\mathrm{~m} / \mathrm{m}) \mathrm{SA}$ as the leading formulation. Minimizing SA content while retaining droplet/mucin interactions is of great importance for efficacy and safety of future ophthalmic drug products.
\end{abstract}

Keywords: cationic nanoemulsions, stearylamine, ophthalmic drug delivery, biocompatibility, mucoadhesion in vitro

Ophthalmic diseases are most commonly treated by topical instillation of eye-drops. The conventional eye-drops are quite simple dosage forms and are well accepted by patients. However, they often raise technical issues, such as solubility, stability and sterility, and clinical issues due to short residence time at the ocular surface and consequent low bioavailability. A significant number of ophthalmic drugs are lipophilic molecules and it is, therefore, challenging to formulate them in the form of conventional eye-drops. Oil-in-water $(\mathrm{o} / \mathrm{w})$ nanoemulsions (NEs) represent one of the formulation approaches to improve ocular bioavailability of lipophilic drugs. Lipophilic drug molecules can be solubilized at the innermost oil phase or at the o/w interface of a NE (1) and the nanometric size of the

\footnotetext{
*Correspondence; e-mail: jlovric@pharma.hr
} 
oil droplets gives rise to a large surface area available for drug diffusion (2). It is believed that after instillation NE breakdown occurs (due to the composition of tears and blinking) which is followed by the release of drug molecules and fusion of the NE oil phase with tear film lipid layer (TFLL). Since TFLL has a much slower turnover rate than tears, the unreleased drug portion remains in the conjunctival sac for a longer time, acting as a drug depot (3). Such NE behavior is especially beneficial for dry eye disease treatment where TFLL is often compromised and NEs can replenish not only the aqueous phase, but also the lipid phase of the tear film (3). A pilot study on 15 volunteers (5 normal and 10 with dry eye symptoms) showed that 4 hours after a single eye-drop instillation of a castor oil NE, castor oil could still be detected in tears (4). Furthermore, NE droplet surface can be modified with cationic lipids or polymers to form positively charged oil droplets. Such cationic NEs have the potential to electrostatically bind to negatively charged ocular surface cells and mucin chains and hence prolong drug residence $(2,3)$. Stearylamine (SA) is a cationic lipid with surface active properties commonly used to produce positively charged liposomes (5) or emulsions (6-8) and it was found to be safe and well tolerated in rabbits after repeated topical ophthalmic administrations (8). Among positively charged polymers chitosan is most commonly used as a NE cationic agent (3), due to its biocompatibility, biodegradability and mucoadhesion (9). The choice of ophthalmically acceptable excipients (i.e. oils, surfactants, cationic lipids or polymers, isotonizing agent) is of utmost importance for successful development of a stable and functional NE formulation rendering the potential to prolong precorneal residence time and improve bioavailability, which is at the same time non-irritant, well-tolerated and comfortable for patients. That is why a deep physicochemical characterization (including measurement of droplets size, size distribution, zeta-potential, pH, osmolarity, surface tension and viscosity) and biopharmaceutical characterization (including in vitro mucoadhesion and biocompatibility) are crucial for the success.

The aim of this work was the development of a cationic NE, that could serve as a vehicle for lipophilic ophthalmic drugs. SA was used as a droplet positive charge inducer providing the interaction of droplets with the ocular mucins and positively influencing NE stability. Nonionic surfactants were selected in order to provide, together with SA, dual electro-steric stabilization of NEs, and therefore enable tuning of SA concentration according to its interaction with mucins and biocompatibility. Therefore, physicochemical and biopharmaceutical characterizations, including in vitro mucoadhesion and biocompatibility, were performed to choose the lead NE formulation with the greatest potential for further studies.

\section{EXPERIMENTAL}

\section{Chemicals}

For NE preparation the following substances were used: castor oil, virgin (Kemig, Croatia), Miglyol ${ }^{\circledR} 812$ (Kemig), sesame oil, super refined (Croda International Pic, United Kingdom), soybean oil, refined (Sigma-Aldrich, Germany), Cremophor ${ }^{\circledR}$ EL (BASF, Germany), Pluronic ${ }^{\circledR}$ F68 (Sigma-Aldrich), Tween ${ }^{\circledR} 60$ (Sigma-Aldrich), Tween ${ }^{\circledR} 80$ (Kemig), glycerol (T.T.T., Croatia) and stearylamine (Sigma-Aldrich). MTT reagent (3-(4,5-dimethylthiazol-2-yl)-2,5-diphenyl tetrazolium bromide) purchased from AppliChem (Germany) was 
used to determine cell viability in in vitro biocompatibility study. Porcine gastric mucin type II (Sigma-Aldrich) was used for in vitro study of mucoadhesion. Hank's balanced salt solution (HBSS) $\mathrm{pH} 7.4$ was prepared as an aqueous solution containing: $\mathrm{KCl}\left(5.37 \mathrm{mmol} \mathrm{L}^{-1}\right)$, $\mathrm{NaHCO}_{3}\left(4.17 \mathrm{mmol} \mathrm{L}^{-1}\right), \mathrm{NaCl}\left(136.89 \mathrm{mmol} \mathrm{L}^{-1}\right), \mathrm{MgSO}_{4} \times 7 \mathrm{H}_{2} \mathrm{O}\left(0.41 \mathrm{mmol} \mathrm{L}^{-1}\right)$, D-glucose monohydrate (5.55 mmol L-1) (all purchased from Kemig), $\mathrm{KH}_{2} \mathrm{PO}_{4}\left(0.44 \mathrm{mmol} \mathrm{L}{ }^{-1}\right.$; Kemika, Croatia), $\mathrm{Na}_{2} \mathrm{HPO}_{4} \times 2 \mathrm{H}_{2} \mathrm{O}\left(0.34 \mathrm{mmol} \mathrm{L}^{-1}\right.$; Fluka Chemie $\mathrm{AG}$, Switzerland), $\mathrm{MgCl}_{2} \times 6 \mathrm{H}_{2} \mathrm{O}$ (0.49 $\mathrm{mmol} \mathrm{L}^{-1}$; Merck, Germany), $\mathrm{CaCl}_{2} \times 2 \mathrm{H}_{2} \mathrm{O}\left(1.26 \mathrm{mmol} \mathrm{L}^{-1}\right.$; Sigma-Aldrich) and HEPES (30.00 $\mathrm{mmol} \mathrm{L}^{-1}$; AppliChem). Simulated tear fluid (STF) $\mathrm{pH} 7.4$ was prepared as an aqueous solution containig: $\mathrm{KCl}\left(18.78 \mathrm{mmol} \mathrm{L}^{-1}\right), \mathrm{NaCl}(116.35 \mathrm{mmol} \mathrm{L}-1), \mathrm{NaHCO}_{3}\left(26.19 \mathrm{mmol} \mathrm{L}^{-1}\right)$ and $\mathrm{CaCl}_{2} \times 2 \mathrm{H}_{2} \mathrm{O}\left(0.54 \mathrm{mmol} \mathrm{L}^{-1}\right)$.

\section{NE preparation}

NEs within this work were produced by a high-energy method using microfluidizer (Model M-110EH-30, Microfluidics ${ }^{\circledR}$, USA). NEs without SA were prepared by the addition of oil $(5 \%, \mathrm{~m} / \mathrm{m})$ to the aqueous surfactant solution $(0.5-5 \%, \mathrm{~m} / \mathrm{m})$ at room temperature under magnetic stirring (Table I). The mixture was then pre-homogenized on Ultra-Tur$\operatorname{rax}^{\circledR}$ (IKA-Werke GmbH \& Company, Germany) during 5 minutes at $6000 \mathrm{rpm}$ and the obtained coarse emulsion was further processed on microfluidizer under the pressure of 1000 bar and 10 cycles. To prepare NEs with SA (SANEs), SA $(0.01-0.3 \%, \mathrm{~m} / \mathrm{m})$ was dissolved in Miglyol ${ }^{\circledR} 812(5 \%, \mathrm{~m} / \mathrm{m})$ by heating to $70{ }^{\circ} \mathrm{C}$. The aqueous solution of Cremophor ${ }^{\circledR}$ EL $(2.5 \%, \mathrm{~m} / \mathrm{m})$ and glycerol $(2.5 \%, \mathrm{~m} / \mathrm{m})$ preheated to the same temperature was added to the oil phase under magnetic stirring and the rest of the procedure was done as for the NEs without SA.

\section{Physicochemical characterization and stability testing}

Droplet size, polydispersity index (PDI) and zeta-potential of NEs were measured by photon correlation spectroscopy (PCS) using Zetasizer Nano Series (Malvern Instruments, United Kingdom) at $25^{\circ} \mathrm{C}$. For that purpose, NE samples were diluted $100 \times(V / V)$ with double distilled water (droplet size and PDI) and $10 \mathrm{mM} \mathrm{NaCl}$ solution (zeta-potential), respectively. $\mathrm{pH}$ was measured on a Seven Multi $\mathrm{pH} /$ conductometer (Mettler Toledo, USA) at $25{ }^{\circ} \mathrm{C}$. NE viscosity was measured using MCR 102 rheometer (Anton Paar, Austria) equipped with a cone-plate measuring device (CP 50-1, trim position $102 \mu \mathrm{m}$ ) over a shear rate range $1-100 \mathrm{~s}^{-1}$ at $25^{\circ} \mathrm{C}$. The viscosity of oils was determined by employing the same method. Surface tension measurements were performed on Krüss K-100C tensiometer (Germany), employing the Du Noüy ring method. All measurements were performed at $25^{\circ} \mathrm{C}$ using a water-circulating bath with temperature stability within $0.02{ }^{\circ} \mathrm{C}$. For stability testing purposes droplet size, PDI, zeta-potential and $\mathrm{pH}$ were measured as described after 30 and 150 -day storage period at $4{ }^{\circ} \mathrm{C}$.

\section{In vitro biocompatibility study}

In vitro biocompatibility study was performed using HCE-T cells (RIKEN Cell Bank, Japan). The cells were cultivated as reported previously $(11,12)$. For in vitro biocompatibility studies two types of cell models were employed, namely 2D and 3D HCE-T cell models. For cultivations of the 2D model, HCE-T cells suspended in supplemented DMEM/F-12 
medium were seeded onto a 96 -well plate $\left(1 \times 10^{4}\right.$ cells per well) and grown until reaching confluence. The culture medium was then aspirated and the cells were rinsed with HBSS (approximately $100 \mu \mathrm{L}$ per well). The cells were then exposed to NE diluted 10× $(V / V)$ in HBSS, as previously described (13), during 30 minutes at $37^{\circ} \mathrm{C}$. The NE samples were then removed, the cells were rinsed with HBSS (approximately $100 \mu \mathrm{L}$ per well), the culture medium was added $(100 \mu \mathrm{L}$ per well) and the cells were left in the incubator until the following day when MTT assay was performed. MTT was dissolved in phosphate buffered saline (PBS, Sigma-Aldrich) to obtain a $6 \mathrm{mM}$ solution and $20 \mu \mathrm{L}$ of such solution were added to each well. The cells were then incubated during 3 hours at $37^{\circ} \mathrm{C}$, after which the medium was aspirated and $100 \mu \mathrm{L}$ of isopropanol was added to each well in order to dissolve the formazan crystals. The absorbance of the formazan solution was measured at 570 $\mathrm{nm}$ with a microplate reader (1420 Multilabel counter VICTOR ${ }^{3}$, Perkin Elmer, USA). The cells incubated in HBSS were used as a control of $100 \%$ cell viability.

For cultivation of the 3D HCE-T model, Transwell ${ }^{\circledR}$ polycarbonate membrane cell culture inserts $\left(0.4 \mu \mathrm{m}\right.$ pore size, $12 \mathrm{~mm}$ diameter, surface area $1.12 \mathrm{~cm}^{2}$, Corning B.V. Life Sciences, Amsterdam, The Netherlands) were used. The 3D HCE-T model was cultivated as reported previously $(11,12)$. Before treatment with the NE samples, the culture medium was aspirated from the basolateral side and the inserts were washed with HBSS. The inserts were then transferred to a new 12-well cell culture plate (Corning B.V. Life Sciences) and incubated during 30 minutes in HBSS ( $0.5 \mathrm{~mL}$ apical side $/ 1.5 \mathrm{~mL}$ basolateral side) at $37^{\circ} \mathrm{C}$. After incubation, HBSS from the apical side was removed and $0.5 \mathrm{~mL}$ of NE sample diluted $10 \times(V V)$ in HBSS, as previously described (13), was added instead and the model was incubated during 30 minutes at $37^{\circ} \mathrm{C}$. After incubation, the test samples were removed from the apical side and the inserts were washed with HBSS, after which the inserts were transferred to a new 12-well plate with a metal plate containing $2 \mathrm{~mL}$ of cell culture medium in the basolateral side, while the apical side was exposed to the air-liquid interface (ALI) overnight. MTT assay was performed according to the protocol previously reported (11, 14). Briefly, after removing the cell culture medium, $0.7 \mathrm{~mL}$ of MTT solution in the cell culture medium $(1.2 \mathrm{mM})$ was added to both apical and basolateral compartment and the model was incubated during 3 hours at $37^{\circ} \mathrm{C}$. After removing the MTT solution, formazan crystals were dissolved in isopropanol $(0.7 \mathrm{~mL}$ in both apical and basolateral compartment) and the absorbance was determined as described for 2D HCE-T cell model above.

\section{In vitro mucoadhesion study}

For a better understanding of NE interaction with mucin an in vitro study was performed as described by Pereira de Sousa et al. (15) with some modifications. Briefly, $1 \%$ $(\mathrm{m} / \mathrm{m})$ mucin dispersion in STF was prepared by overnight stirring at room temperature. NEs were mixed with the mucin dispersion in 40:7 (V/V) ratio and left under magnetic stirring at $300 \mathrm{rpm}$ during 20 minutes at room temperature. Samples were taken at 5 and 20 minutes and droplet size and zeta-potential were measured as described above.

\section{RESULTS AND DISCUSSION}

NE technology has an increasing influence in every aspect of drug delivery (16-18), particularly in ophthalmic drug delivery $(2,19)$. Physicochemical properties affecting in 
vivo performance of an ophthalmic NE include droplet size, size distribution and zeta-potential, formulation viscosity profile as a function of applied shear, $\mathrm{pH}$, osmolarity, and surface tension $(20,21)$. In order to develop a stable cationic NE with SA as a carrier of positive charge, we first performed screening of ophthalmically acceptable oils and nonionic surfactants in search for primary formulation with small droplet size and low PDI value.

\section{Screening of oils and nonionic surfactants for NE preparation}

Four different types of oils (castor oil, Miglyol ${ }^{\circledR} 812$, sesame oil and soybean oil) and surfactants (Cremophor ${ }^{\circledR}$ EL, Pluronic ${ }^{\circledR}$ F68, Tween ${ }^{\circledR} 60$ and Tween ${ }^{\circledR} 80$ ) were used to produce NEs using microfluidizer (Table I). While the oil concentration was fixed at $5 \%(\mathrm{~m} / \mathrm{m})$, since higher oil concentrations tend to cause blurred vision when NEs are applied to the eye (1), the surfactant concentration varied between 0.5 and $5 \%(\mathrm{~m} / \mathrm{m})$. As can be seen from Table I, the oil type had a significant influence on the NE droplet size, which could be ascribed to the difference in the oil viscosity. It was already stated that higher viscosities lead to flow resistance in the chamber of a microfluidizer which reduces the rate and efficiency of droplet disruption, resulting in larger droplet formation (22). The viscosity values measured for castor oil, Miglyol ${ }^{\circledR} 812$, sesame and soybean oil were $704.37 \pm 14.85,22.91 \pm 0.05$, $55.89 \pm 0.13$ and $54.91 \pm 0.21 \mathrm{mPa}$ s, respectively. Thus, the largest droplets were obtained with castor oil, which had the highest viscosity, and the smallest droplets were produced with Miglyol ${ }^{\circledR} 812$, which had the lowest viscosity. Since smaller oil droplet size contributes to the NE stability and also leads to an increase in the total surface area available for drug diffusion (2), Miglyol ${ }^{\circledR} 812$ was chosen as the oil phase for further studies. While the type of nonionic surfactants did not seem to have a strong impact on the droplet size, the increase in the surfactant concentration had a significant influence on the droplet size reduction, as already reported elsewhere $(23,24)$. This can be explained by the fact that an excess of surfactant in the bulk NE outer phase is available to cover any new droplet surface formed during homogenization and by the fact that the droplet surface is covered more rapidly (24). Also, lowering the interfacial tension through the use of surfactants may facilitate droplet disruption and formation of smaller droplets (25). Zeta-potential of all the NEs produced was close to zero or slightly negative, probably due to the preferential adsorption of $\mathrm{OH}^{-}$ions on the droplet surface, as explained elsewhere (26). From all the NEs prepared the NE formulation with $5 \%(\mathrm{~m} / \mathrm{m})$ of Miglyol $^{\circledR} 812$ and $2.5 \%(\mathrm{~m} / \mathrm{m})$ of Cremophor ${ }^{\circledR}$ EL was chosen for further studies because it had the lowest droplet size among the NE formulations with PDI value lower than 0.2.

\section{Preparation and physicochemical characterization of cationic stearylamine NES (SANEs)}

After selecting the primary formulation stabilized with nonionic surfactant only, the selection of SA concentration for SANE preparation was performed. A total of $4 \mathrm{NE}$ formulations of Miglyol ${ }^{\circledR} 812(5 \%, \mathrm{~m} / \mathrm{m})$, Cremophor ${ }^{\circledR}$ EL $(2.5 \%, \mathrm{~m} / \mathrm{m})$ and SA $(0.01,0.05,0.1$ and $0.3 \%, \mathrm{~m} / \mathrm{m})$ with glycerol as a tonicity agent $(2.5 \%, \mathrm{~m} / \mathrm{m})$ were prepared (Table II) and a detailed physicochemical characterization was performed. The obtained SANEs were highly fluid and homogenous with milky-white appearance with osmolarity in the physiological range of tear film. All SANE formulations were characterized by small droplet size (81.03 to $95.6 \mathrm{~nm}$ ) and appropriate PDI (0.139 to 0.251) with droplet size and PDI increasing 
B. Jurišić Dukovski et al.: In vitro evaluation of stearylamine cationic nanoemulsions for improved ocular drug delivery, Acta Pharm. 69 (2019) 621-634.

Table I. Droplet size, polydispersity index (PDI) and zeta-potential of nanoemulsions prepared with different oil type, surfactant type and surfactant concentration

\begin{tabular}{|c|c|c|c|c|c|}
\hline Oil type & Surfactant type & $\begin{array}{c}\text { Surfactant } \\
\text { concentration (\%) }\end{array}$ & $\begin{array}{l}\text { Droplet size } \\
\text { (nm) }\end{array}$ & PDI & $\begin{array}{l}\text { Zeta-potential } \\
(\mathrm{mV})\end{array}$ \\
\hline \multirow{16}{*}{ Castor oil } & \multirow{4}{*}{ Cremophor $^{\circledR}$ EL } & 0.5 & $374.8 \pm 1.6$ & $0.205 \pm 0.051$ & $-11.2 \pm 0.5$ \\
\hline & & 1 & $281.0 \pm 2.8$ & $0.270 \pm 0.038$ & $-8.6 \pm 0.7$ \\
\hline & & 2.5 & $231.1 \pm 3.3$ & $0.448 \pm 0.119$ & $-7.2 \pm 0.4$ \\
\hline & & 5 & $212.5 \pm 2.7$ & $0.419 \pm 0.006$ & $-6.7 \pm 0.5$ \\
\hline & \multirow{4}{*}{ Pluronic $^{\circledR}$ F68 } & 0.5 & $407.6 \pm 3.6$ & $0.315 \pm 0.054$ & $-12.2 \pm 0.9$ \\
\hline & & 1 & $340.9 \pm 2.2$ & $0.268 \pm 0.058$ & $-9.9 \pm 0.9$ \\
\hline & & 2.5 & $258.3 \pm 2.5$ & $0.212 \pm 0.034$ & $-6.0 \pm 0.7$ \\
\hline & & 5 & $223.5 \pm 3.9$ & $0.268 \pm 0.021$ & $-5.0 \pm 0.4$ \\
\hline & \multirow{4}{*}{ Tween $^{\circledR} 60$} & 0.5 & $458.0 \pm 2.8$ & $0.100 \pm 0.071$ & $-7.5 \pm 0.7$ \\
\hline & & 1 & $380.9 \pm 4.2$ & $0.235 \pm 0.075$ & $-5.9 \pm 0.1$ \\
\hline & & 2.5 & $275.5 \pm 3.0$ & $0.238 \pm 0.026$ & $-5.5 \pm 0.1$ \\
\hline & & 5 & $227.6 \pm 4.2$ & $0.323 \pm 0.048$ & $-5.0 \pm 0.3$ \\
\hline & \multirow{4}{*}{ Tween ${ }^{\circledR} 80$} & 0.5 & $448.7 \pm 11.4$ & $0.250 \pm 0.247$ & $-8.6 \pm 0.4$ \\
\hline & & 1 & $367.7 \pm 3.0$ & $0.274 \pm 0.069$ & $-3.1 \pm 0.5$ \\
\hline & & 2.5 & $282.0 \pm 3.7$ & $0.233 \pm 0.018$ & $-2.5 \pm 0.6$ \\
\hline & & 5 & $238.5 \pm 1.7$ & $0.351 \pm 0.069$ & $-2.2 \pm 0.2$ \\
\hline \multirow{16}{*}{ Miglyol $^{\circledR} 812$} & \multirow{4}{*}{ Cremophor $^{\circledR}$ EL } & 0.5 & $205.3 \pm 2.1$ & $0.089 \pm 0.007$ & $-7.0 \pm 0.7$ \\
\hline & & 1 & $158.7 \pm 2.5$ & $0.093 \pm 0.020$ & $-4.5 \pm 0.5$ \\
\hline & & 2.5 & $98.5 \pm 0.7$ & $0.160 \pm 0.007$ & $-4.3 \pm 0.7$ \\
\hline & & 5 & $65.1 \pm 0.7$ & $0.216 \pm 0.002$ & $-2.2 \pm 0.5$ \\
\hline & \multirow{4}{*}{ Pluronic ${ }^{\circledR}$ F68 } & 0.5 & $225.5 \pm 1.4$ & $0.135 \pm 0.019$ & $-1.3 \pm 0.3$ \\
\hline & & 1 & $190.8 \pm 1.8$ & $0.134 \pm 0.008$ & $-1.3 \pm 0.5$ \\
\hline & & 2.5 & $137.9 \pm 0.7$ & $0.143 \pm 0.012$ & $-1.9 \pm 0.6$ \\
\hline & & 5 & $95.9 \pm 0.6$ & $0.171 \pm 0.023$ & $-1.3 \pm 0.3$ \\
\hline & \multirow{4}{*}{ Tween $^{\circledR} 60$} & 0.5 & $197.3 \pm 2.4$ & $0.115 \pm 0.031$ & $-14.1 \pm 0.6$ \\
\hline & & 1 & $160.6 \pm 1.4$ & $0.144 \pm 0.010$ & $-12.3 \pm 0.6$ \\
\hline & & 2.5 & $114.7 \pm 1.5$ & $0.289 \pm 0.030$ & $-11.0 \pm 0.6$ \\
\hline & & 5 & $79.5 \pm 0.7$ & $0.348 \pm 0.024$ & $-8.2 \pm 0.5$ \\
\hline & \multirow{4}{*}{ Tween $^{\circledast} 80$} & 0.5 & $196.3 \pm 1.1$ & $0.131 \pm 0.005$ & $-10.7 \pm 0.5$ \\
\hline & & 1 & $154.6 \pm 1.3$ & $0.184 \pm 0.027$ & $-6.0 \pm 0.5$ \\
\hline & & 2.5 & $108.5 \pm 0.5$ & $0.286 \pm 0.020$ & $-2.2 \pm 0.6$ \\
\hline & & 5 & $78.2 \pm 0.7$ & $0.361 \pm 0.046$ & $-1.4 \pm 0.8$ \\
\hline
\end{tabular}




\begin{tabular}{|c|c|c|c|c|c|}
\hline \multirow{16}{*}{ Sesame oil } & \multirow{4}{*}{ Cremophor $^{\circledR}$ EL } & 0.5 & $247.6 \pm 3.9$ & $0.093 \pm 0.039$ & $-2.9 \pm 0.6$ \\
\hline & & 1 & $198.5 \pm 3.0$ & $0.134 \pm 0.016$ & $-2.5 \pm 0.4$ \\
\hline & & 2.5 & $132.2 \pm 1.9$ & $0.271 \pm 0.023$ & $-2.3 \pm 0.7$ \\
\hline & & 5 & $92.7 \pm 0.8$ & $0.371 \pm 0.030$ & $-1.9 \pm 0.6$ \\
\hline & \multirow{4}{*}{ Pluronic ${ }^{\circledR}$ F68 } & 0.5 & $257.9 \pm 4.5$ & $0.140 \pm 0.080$ & $-2.2 \pm 0.5$ \\
\hline & & 1 & $231.2 \pm 4.6$ & $0.114 \pm 0.031$ & $-1.9 \pm 0.5$ \\
\hline & & 2.5 & $182.2 \pm 2.7$ & $0.188 \pm 0.030$ & $-1.0 \pm 0.2$ \\
\hline & & 5 & $146.6 \pm 4.3$ & $0.245 \pm 0.113$ & $-0.9 \pm 0.9$ \\
\hline & \multirow{4}{*}{ Tween $^{\circledR} 60$} & 0.5 & $243.1 \pm 6.1$ & $0.016 \pm 0.016$ & $-5.4 \pm 0.5$ \\
\hline & & 1 & $205.4 \pm 2.7$ & $0.108 \pm 0.052$ & $-7.3 \pm 0.6$ \\
\hline & & 2.5 & $143.6 \pm 3.9$ & $0.222 \pm 0.002$ & $-6.1 \pm 0.4$ \\
\hline & & 5 & $86.8 \pm 1.8$ & $0.349 \pm 0.034$ & $-6.2 \pm 0.6$ \\
\hline & \multirow{4}{*}{ Tween ${ }^{\circledR} 80$} & 0.5 & $233.8 \pm 2.7$ & $0.099 \pm 0.032$ & $-3.2 \pm 0.5$ \\
\hline & & 1 & $193.5 \pm 3.2$ & $0.105 \pm 0.008$ & $-2.3 \pm 0.5$ \\
\hline & & 2.5 & $138.3 \pm 2.4$ & $0.199 \pm 0.020$ & $-2.9 \pm 0.5$ \\
\hline & & 5 & $93.0 \pm 2.1$ & $0.340 \pm 0.028$ & $-2.7 \pm 0.5$ \\
\hline \multirow{16}{*}{ Soybean oil } & \multirow{4}{*}{ Cremophor $^{\circledR}$ EL } & 0.5 & $236.2 \pm 3.3$ & $0.148 \pm 0.090$ & $-7.1 \pm 0.2$ \\
\hline & & 1 & $190.8 \pm 3.1$ & $0.097 \pm 0.036$ & $-5.2 \pm 0.7$ \\
\hline & & 2.5 & $118.4 \pm 2.4$ & $0.181 \pm 0.019$ & $-4.2 \pm 0.8$ \\
\hline & & 5 & $87.8 \pm 1.3$ & $0.383 \pm 0.011$ & $-3.7 \pm 0.3$ \\
\hline & \multirow{4}{*}{ Pluronic $^{\circledR}$ F68 } & 0.5 & $253.7 \pm 6.3$ & $0.124 \pm 0.006$ & $-4.4 \pm 0.3$ \\
\hline & & 1 & $229.1 \pm 6.2$ & $0.121 \pm 0.033$ & $-3.4 \pm 0.5$ \\
\hline & & 2.5 & $179.9 \pm 4.4$ & $0.050 \pm 0.040$ & $-2.8 \pm 0.5$ \\
\hline & & 5 & $145.4 \pm 2.4$ & $0.212 \pm 0.045$ & $-3.6 \pm 1.2$ \\
\hline & \multirow{4}{*}{ Tween $^{\circledR} 60$} & 0.5 & $238.3 \pm 3.8$ & $0.127 \pm 0.022$ & $-6.4 \pm 0.4$ \\
\hline & & 1 & $195.6 \pm 2.8$ & $0.167 \pm 0.003$ & $-5.2 \pm 0.3$ \\
\hline & & 2.5 & $115.3 \pm 1.3$ & $0.336 \pm 0.039$ & $-5.5 \pm 0.4$ \\
\hline & & 5 & $83.8 \pm 0.9$ & $0.429 \pm 0.049$ & $-5.5 \pm 0.3$ \\
\hline & \multirow{4}{*}{ Tween $^{\circledR} 80$} & 0.5 & $245.1 \pm 5.9$ & $0.076 \pm 0.055$ & $-9.0 \pm 0.3$ \\
\hline & & 1 & $205.9 \pm 5.1$ & $0.131 \pm 0.021$ & $-4.0 \pm 0.6$ \\
\hline & & 2.5 & $149.2 \pm 3.8$ & $0.231 \pm 0.007$ & $-1.6 \pm 0.2$ \\
\hline & & 5 & $99.8 \pm 2.4$ & $0.314 \pm 0.017$ & $-0.9 \pm 0.8$ \\
\hline
\end{tabular}

Mean \pm SD, $n=2$ 
with the increase of SA concentration (Table II). As expected, zeta-potential also increased from 3.1 to $25.5 \mathrm{mV}$ with the SA concentration increase from 0.01 to $0.3 \%(\mathrm{~m} / \mathrm{m})$. Zeta-potential of droplets influences formulation precorneal residence and stability at the ocular surface as well as formulation stability during storage. For all SANE formulations, $\mathrm{pH}$ was in the range acceptable for ophthalmic administration. SANE formulations behaved as Newtonian systems and their viscosity, as determined by rotational rheological characterization, was in the range similar to the viscosity of water with a slight increase with the increase in SA concentration. Low formulation viscosity enables dosing accuracy and ease of eye-drop administration. Surface tension is an important physicochemical formulation parameter that determines spreading of a formulation across the ocular surface and also influences capillary drainage through the nasolacrimal ducts, affecting precorneal residence time of the instilled formulation (20). As expected, with the increase in cationic surfactant concentration, the surface tension of SANE formulation decreased. The surface tension of the tear film has a physiological range of $40-46 \mathrm{mN} / \mathrm{m}(27,28)$. Generally, higher surface tension values correspond to lower tear film stability, as it is the case in dry eye disease, where a surface tension range of $44-53 \mathrm{mN} \mathrm{m}^{-1}$ has been reported $(29,30)$. The surface tension of an ophthalmic formulation should be close to $35 \mathrm{mN} \mathrm{m}^{-1}$, since there are indications that the administration of formulations with lower surface tension may be painful and uncomfortable $(30,31)$.

Physical stability of SANE formulations was followed during 150-day storage at $4{ }^{\circ} \mathrm{C}$. The formulations did not show any difference in their visual appearance, i.e. no creaming or phase separation was observed. The PCS analyses confirmed that during the storage period, the droplets stayed in the nanometer range $(<100 \mathrm{~nm})$ with only a minor size increase $(\sim 10 \mathrm{~nm})$, no significant changes in droplet size distribution (PDI < 0.25) nor zetapotential (Fig. 1), proving therefore a satisfactory formulation stability. As a role of thumb, droplet zeta-potential either above $30 \mathrm{mV}$ or below $-30 \mathrm{mV}$ is considered a good indicator of long-term stability of a charged NE (16). The satisfactory formulation physical stability of the investigated SANE formulations, therefore, confirms an effective dual electro-steric stabilization. As an indicator of chemical stability, the $\mathrm{pH}$ value was also determined. In all the formulations a decrease in $\mathrm{pH}$ was observed, however, $\mathrm{pH}$ values stayed in the ophthalmically acceptable range (6.07-8.45).

Table II. Droplet size, polydispersity index (PDI), zeta-potential, $p H$, viscosity and surface tension of nanoemulsions with different stearylamine ( $S A)$ concentration

\begin{tabular}{ccccccc}
\hline SA (\%) & $\begin{array}{c}\text { Droplet size } \\
(\mathrm{nm})\end{array}$ & PDI & $\begin{array}{c}\text { Zeta-potential } \\
(\mathrm{mV})\end{array}$ & $\mathrm{pH}$ & $\begin{array}{c}\text { Viscosity } \\
(\mathrm{mPa})\end{array}$ & $\begin{array}{c}\text { Surface } \\
\text { tension } \\
\left(\mathrm{mN} \mathrm{m}^{-1}\right)\end{array}$ \\
\hline 0 & $81.2 \pm 0.4$ & $0.110 \pm 0.007$ & $-2.0 \pm 0.5$ & $6.76 \pm 0.12$ & $1.32 \pm 0.01$ & $34.53 \pm 1.16$ \\
0.01 & $81.03 \pm 0.4$ & $0.139 \pm 0.017$ & $3.1 \pm 0.5$ & $6.82 \pm 0.14$ & $1.40 \pm 0.02$ & $34.98 \pm 0.38$ \\
0.05 & $86.0 \pm 0.4$ & $0.228 \pm 0.005$ & $13.2 \pm 1.2$ & $7.03 \pm 0.12$ & $1.71 \pm 0.07$ & $34.57 \pm 0.37$ \\
0.1 & $89.9 \pm 0.5$ & $0.236 \pm 0.005$ & $20.3 \pm 1.3$ & $7.78 \pm 0.19$ & $3.31 \pm 0.32$ & $32.67 \pm 0.62$ \\
0.3 & $95.6 \pm 2.8$ & $0.251 \pm 0.012$ & $25.5 \pm 2.15$ & $8.69 \pm 0.31$ & $2.80 \pm 0.30$ & $31.29 \pm 1.02$ \\
\hline
\end{tabular}

Mean \pm SD, $n=2$ 
a)

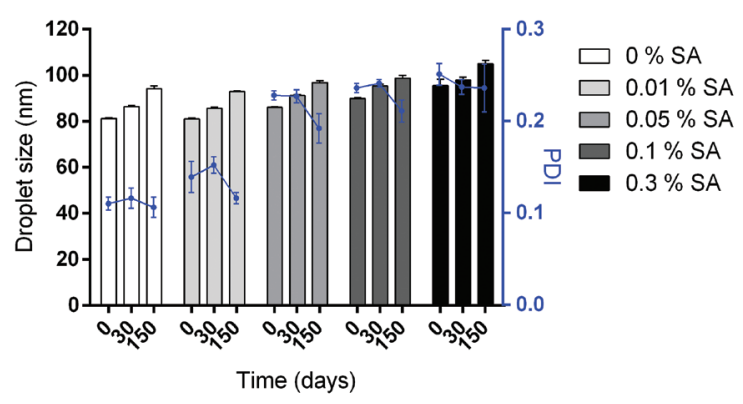

b)

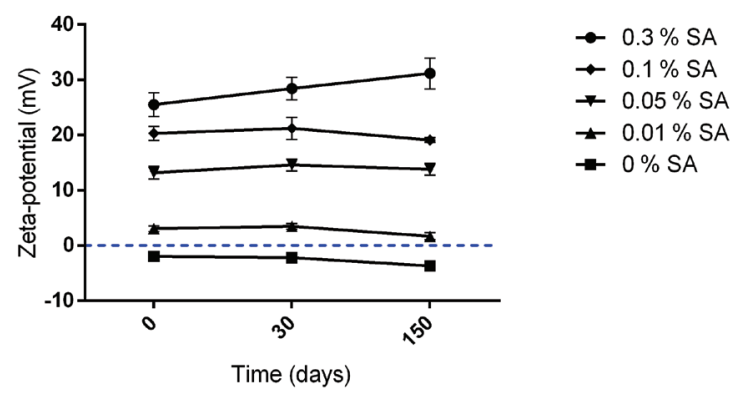

Fig. 1. a) Droplet size and polydispersity index (PDI), b) zeta-potential of SANE formulations measured at day 0, 30 and 150. Data are expressed as mean \pm SD $(n=2)$. NE without SA $(0 \%)$ is plotted as control formulation.

\section{In vitro biocompatibility determination}

The most extensively characterized human-derived cell line used in corneal biocompatibility and transcorneal permeability studies is the immortalized human corneal epithelial cell line (HCE-T) (11). The majority of in vitro biocompatibility screenings is currently undertaken using cells cultured in a two-dimensional (2D) environment (32). However, this does not accurately reflect the three dimensional (3D) structure of the corneal epithelium. The use of inadequate experimental tools can lead to wrong conclusions about formulation biocompatibility. Therefore, SANE formulation biocompatibility was screened using both 2D and 3D HCE-T cell-based model. As shown in Fig. 2, cell viability in the 2D HCE-T model was severely affected in the presence of formulations, and the negative formulation effect on cell viability increased in relation to SA content. However, SANE formulations in the same concentration irrespective to SA content were found to be biocompatible with the 3D HCE-T cell-based model.

\section{In vitro mucoadhesion determination}

Beneficial effects of NEs on eye-related bioavailability will depend on the residence time of a formulation at the ocular surface. SA, as a cationic surfactant, has the potential to interact with mucins present in the tear fluid. Mucins are high-molecular-mass glycopro- 


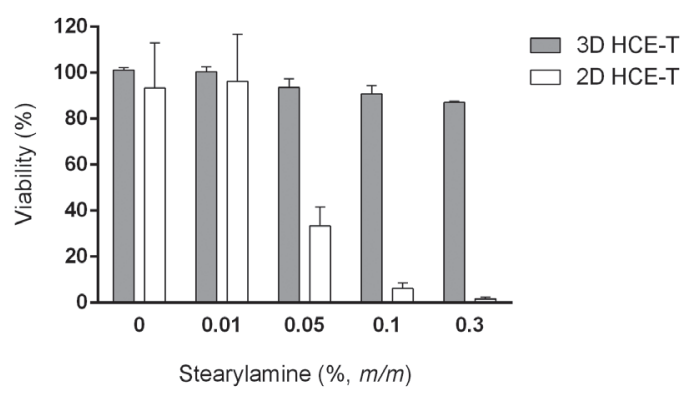

Fig. 2. 3D $(n=2)$ and 2D $(n=5)$ HCE-T model viability $(\%)$ determined by MTT assay after 30-minute incubation with NE diluted 10 times with HBSS pH 7.4. Cells incubated in HBSS only were used as a control of $100 \%$ cell viability. Data are expressed as mean \pm SD.

teins with polysaccharide side chains usually terminated with either fucose or sialic acid, which makes them negatively charged at physiological $\mathrm{pH}$ (33). In order to determine mucoadhesion potential of SANE formulations, we investigated the electrostatic interactions occurring between SANE droplets and diluted mucins by adapting the method developed by Bernkop-Schnürch group (15) to mimic the conditions at the ocular surface. More precisely, SANE formulations were mixed with $1 \%(\mathrm{~m} / \mathrm{m})$ mucin dispersion in STF in 40:7 ( V/V) ratio and the mucin-droplet interaction was followed during 20 minutes (Fig. 3). This ratio was based on the approximate volumes of an eye-drop $(40 \mu \mathrm{L})$ and a tear film $(7 \mu \mathrm{L})(34,35)$. In a short time period after eye-drop instillation, positively charged oil droplets should electrostatically interact with negatively charged mucins in order to decrease their clearance from the ocular surface. This droplet/mucin interaction should be detectable in vitro by an increase in droplet size and a decrease in droplet zeta-potential. This innovative in vitro method for determination of NE mucoadhesive properties was used as an alternative to the most frequently used in vitro methods, such as tensile strength and rheological method (36). Tensile strength has been the most extensively used in vitro method for the determination of bioadhesive interactions and it can be performed on solid and semisolid materials or formulations. Besides the need to adjust certain parameters (force, contact time and withdrawal speed) depending on the tested sample and consequent incomparability of the results obtained among distinct samples (36), this method is not appropriate for liquid samples, and was thus not used within this study. Another commonly used in vitro method is the rheological method, which can detect interactions between mucin and polymers in terms of viscosity increase due to synergism $(36,37)$. However, due to the fact that our NE formulations did not contain any polymeric material, this rheological method was also not a good choice, since it could underestimate NE mucoadhesive properties and give inconsistent and confusing results. The innovative in vitro method used within this study is appropriate for liquid samples containing positively charged nanomaterial. However, it could not be used to test mucoadhesion of solid or semisolid formulations, nor formulations that base their mucoadhesive properties on mechanisms other than electrostatic interaction. In vivo studies, that are usually based on measurement of formulation residence time on the ocular surface, are needed to confirm the results obtained by in vitro methods, even though such methods do not provide an insight in the mucoadhesion mechanism (36). 
a)

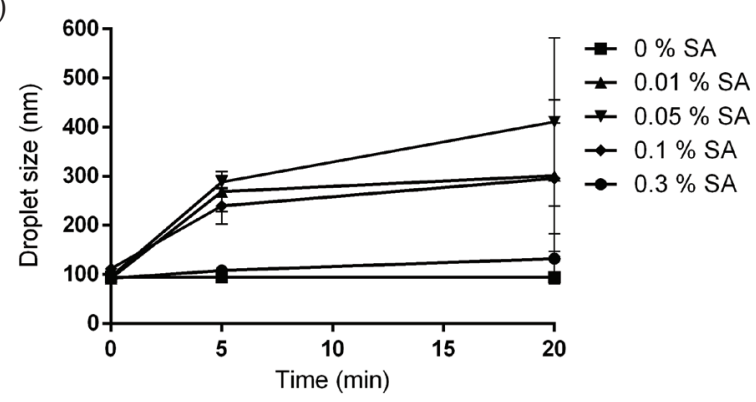

b)

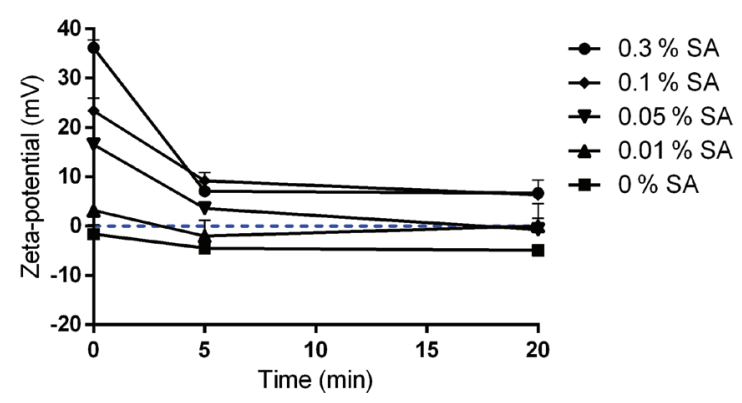

Fig. 3. a) Droplet size and b) zeta-potential of nanoemulsions measured before and 5 and 20 minutes after mixing with $1 \%(\mathrm{~m} / \mathrm{m})$ mucin dispersion in STF in 40:7 (V/V) ratio. NE without SA $(0 \%)$ was used as control formulation. Data are expressed as mean $\pm \mathrm{SD}$.

A drastic change in studied physicochemical parameters was observed immediately 5 minutes after mixing SANE formulations with mucins (Fig. 3). The droplets reached a size above $200 \mathrm{~nm}$ for SANE formulations with SA content up to $0.1 \%$. Interestingly, the droplet size increase was not observed for the formulation with the highest SA content. Droplet zeta-potential decreased significantly for all SANE formulations. The NE formulation without SA was used as a negative control and no significant change in studied physicochemical parameters was observed throughout the whole test period. Therefore, the change in size and zeta-potential detected can be ascribed to droplet/mucin interaction mediated by SA positively charged groups at the droplet interface.

\section{CONCLUSIONS}

Physicochemical parameters (droplet size $<100 \mathrm{~nm}$, PDI $<0.25$, zeta-potential $\sim 13 \mathrm{mV}$, $\mathrm{pH} \sim 7$, surface tension $\sim 35 \mathrm{mN} \mathrm{m}^{-1}$ ) and stability profile pointed out SANE formulation with $0.05 \%$ SA as the leading formulation. This was confirmed in in vitro mucoadhesion study where substantial droplet/mucin interaction was determined for the mentioned SANE formulation. The selected formulation was also found to be biocompatible with the 3D HCE-T cell-based model of corneal epithelium. Minimizing SA content while retaining droplet/mucin interactions is of great importance for efficacy and safety of future ophthalmic drug products. 
Acknowledgments. - The authors are grateful to R\&D PLIVA Croatia Ltd. for generously providing the use of Microfluidics ${ }^{\circledR}$ microfluidizer. The authors also acknowledge the participation of students Matea Krpan and Glorija Parmać in the screening of oils and nonionic surfactants for NE preparation. This work was supported by the project entitled Topical nanodelivery systems funded by the University of Zagreb (Z169).

\section{REFERENCES}

1.S. Tamilvanan and S. Benita, The potential of lipid emulsion for ocular delivery of lipophilic drugs, Eur. J. Pharm. Biopharm. 58 (2004) 357-368; https://doi.org/10.1016/J.EJPB.2004.03.033

2. F. Lallemand, P. Daull, S. Benita, R. Buggage and J.-S. Garrigue, Successfully improving ocular drug delivery using the cationic nanoemulsion, Novasorb, J. Drug Deliv. 2012 (2012) 604204; https:// doi.org/10.1155/2012/604204

3. L. Gan, J. Wang, M. Jiang, H. Bartlett, D. Ouyang, F. Eperjesi, J. Liu and Y. Gan, Recent advances in topical ophthalmic drug delivery with lipid-based nanocarriers, Drug Discov. Today 18 (2013) 290-297; https://doi.org/10.1016/J.DRUDIS.2012.10.005

4. C. Maïssa, M. Guillon, P. Simmons and J. Vehige, Effect of castor oil emulsion eyedrops on tear film composition and stability, Contact Lens Anterior Eye 33 (2010) 76-82; https://doi.org/10.1016/j. clae.2009.10.005

5. A. Manosroi, K. Podjanasoonthon and J. Manosroi, Development of novel topical tranexamic acid liposome formulations, Int. J. Pharm. 235 (2002) 61-70; https://doi.org/10.1016/S0378-5173(01)00980-2

6. S. C. de Araújo, A. C. A. de Mattos, H. F. Teixeira, P. M. Z. Coelho, D. L. Nelson and M. C. de Oliveira, Improvement of in vitro efficacy of a novel schistosomicidal drug by incorporation into nanoemulsions, Int. J. Pharm. 337 (2007) 307-315; https://doi.org/10.1016/J.IJPHARM.2007.01.009

7. M. Fraga, M. Laux, B. Zandoná, G. R. Santos, C. dos Santos Giuberti, M. C. de Oliveira, U. Matte and H. Ferreira Teixeira, Optimization of stearylamine-based nanoemulsions obtained by spontaneous emulsification process as nucleic acids delivery systems, J. Drug Deliv. Sci. Technol. 18 (2008) 398-403; https://doi.org/10.1016/S1773-2247(08)50078-5

8. S. H. Klang, J. Frucht-Pery, A. Hoffman and S. Benita, Physicochemical characterization and acute toxicity evaluation of a positively-charged submicron emulsion vehicle, J. Pharm. Pharmacol. 46 (1994) 986-993; https://doi.org/10.1111/j.2042-7158.1994.tb03254.x

9. I. A. Sogias, A. C. Williams and V. V Khutoryanskiy, Why is chitosan mucoadhesive?, Biomacromolecules 9 (2008) 1837-1842; https://doi.org/10.1021/bm800276d

10. W. T. Liau and A. M. Kasko, Poly(methyl 6-acryloyl- $\beta$-D-glucosaminoside) as a cationic glycomimetic of chitosan, Biomacromolecules 18 (2017) 4133-4140; https://doi.org/10.1021/acs.biomac.7b01191

11. M. Juretić, B. Jurišić Dukovski, I. Krtalić, S. Reichl, B. Cetina-Čižmek, J. Filipović-Grčić, J. Lovrić and I. Pepić, HCE-T cell-based permeability model: A well-maintained or a highly variable barrier phenotype?, Eur. J. Pharm. Sci. 104 (2017) 23-30; https://doi.org/10.1016/J.EJPS.2017.03.018

12. M. Juretić, B. Cetina-Čižmek, J. Filipović-Grčić, A. Hafner, J. Lovrić and I. Pepić, Biopharmaceutical evaluation of surface active ophthalmic excipients using in vitro and ex vivo corneal models, Eur. J. Pharm. Sci. 120 (2018) 133-141; https://doi.org/10.1016/J.EJPS.2018.04.032

13. K. Kinnunen, A. Kauppinen, N. Piippo, A. Koistinen, E. Toropainen and K. Kaarniranta, Cationorm shows good tolerability on human HCE-2 corneal epithelial cell cultures, Exp. Eye Res. 120 (2014) 82-89; https://doi.org/10.1016/J.EXER.2014.01.006

14. A. Pauly, M. Meloni, F. Brignole-Baudouin, J.-M. Warnet and C. Baudouin, Multiple endpoint analysis of the 3D-reconstituted corneal epithelium after treatment with benzalkonium chloride: Early detection of toxic damage, Invest. Ophthalmol. Vis. Sci. 50 (2009) 1644-1652; Retrieved from http://dx.doi.org/10.1167/iovs.08-2992 
15. I. Pereira de Sousa, C. Steiner, M. Schmutzler, M. D. Wilcox, G. J. Veldhuis, J. P. Pearson, C. W. Huck, W. Salvenmoser and A. Bernkop-Schnürch, Mucus permeating carriers: formulation and characterization of highly densely charged nanoparticles, Eur. J. Pharm. Biopharm. 97 (2015) 273279; https://doi.org/10.1016/J.EJPB.2014.12.024

16. Y. Singh, J. G. Meher, K. Raval, F. A. Khan, M. Chaurasia, N. K. Jain and M. K. Chourasia, Nanoemulsion: Concepts, development and applications in drug delivery, J. Control. Release 252 (2017) 28-49; https://doi.org/10.1016/j.jconrel.2017.03.008

17. V. K. Rai, N. Mishra, K. S. Yadav and N. P. Yadav, Nanoemulsion as pharmaceutical carrier for dermal and transdermal drug delivery: Formulation development, stability issues, basic considerations and applications, J. Control. Release 270 (2018) 203-225; https://doi.org/10.1016/J.JCONREL.2017.11.049

18. S. M. Đorđević, A. Santrač, N. D. Cekić, B. D. Marković, B. Divović, T. M. Ilić, M. M. Savić and S. D. Savić, Parenteral nanoemulsions of risperidone for enhanced brain delivery in acute psychosis: Physicochemical and in vivo performances, Int. J. Pharm. 533 (2017) 421-430; https://doi. org/10.1016/J.IJPHARM.2017.05.051

19. L. Gan, J. Wang, M. Jiang, H. Bartlett, D. Ouyang, F. Eperjesi, J. Liu and Y. Gan, Recent advances in topical ophthalmic drug delivery with lipid-based nanocarriers, Drug Discov. Today 18 (2013) 290-297; https://doi.org/10.1016/J.DRUDIS.2012.10.005

20. R. L. Walenga, A. H. Babiskin, X. Zhang, M. Absar, L. Zhao and R. A. Lionberger, Impact of Vehicle Physicochemical Properties on Modeling-Based Predictions of Cyclosporine Ophthalmic Emulsion Bioavailability and Tear Film Breakup Time, J. Pharm. Sci. 108 (2019) 620-629; https://doi. org/10.1016/J.XPHS.2018.10.034

21. H. Qu, J. Wang, Y. Wu, J. Zheng, Y. S. R. Krishnaiah, M. Absar, S. Choi, M. Ashraf, C. N. Cruz and $\mathrm{X}$. Xu, Asymmetric flow field flow fractionation for the characterization of globule size distribution in complex formulations: A cyclosporine ophthalmic emulsion case, Int. J. Pharm. 538 (2018) 215-222; https://doi.org/10.1016/J.IJPHARM.2018.01.012

22. T. J. Wooster, M. Golding and P. Sanguansri, Impact of Oil Type on Nanoemulsion Formation and Ostwald Ripening Stability, Langmuir 24 (2008) 12758-12765; https://doi.org/10.1021/la801685v

23. S. Uluata, E. A. Decker and D. J. McClements, Optimization of Nanoemulsion Fabrication Using Microfluidization: Role of Surfactant Concentration on Formation and Stability, Food Biophys. 11 (2016) 52-59; https://doi.org/10.1007/s11483-015-9416-1

24. H. D. Silva, M. A. Cerqueira and A. A. Vicente, Influence of surfactant and processing conditions in the stability of oil-in-water nanoemulsions, J. Food Eng. 167 (2015) 89-98; https://doi.org/10.1016/j. jfoodeng.2015.07.037

25. S. Brösel and H. Schubert, Investigations on the role of surfactants in mechanical emulsification using a high-pressure homogenizer with an orifice valve, Chem. Eng. Process. Process Intensif. 38 (1999) 533-540; https://doi.org/10.1016/S0255-2701(99)00050-1

26. J.-P. Hsu and A. Nacu, Behavior of soybean oil-in-water emulsion stabilized by nonionic surfactant, J. Colloid Interface Sci. 259 (2003) 374-381; https://doi.org/10.1016/S0021-9797(02)00207-2

27. J. M. Tiffany, N. Winter and G. Bliss, Tear film stability and tear surface tension, Curr. Eye Res. 8 (1989) 507-515; https://doi.org/10.3109/02713688909000031

28. B. Nagyová and J. M. Tiffany, Components responsible for the surface tension of human tears, Curr. Eye Res. 19 (1999) 4-11; https://doi.org/10.1076/ceyr.19.1.4.5341

29. A. Puinhas, P. Sampaio, E. M. S. Castanheira, M. E. C. D. Real Oliveira and M. Lira, Comparison of IgA, TNF- $\alpha$ and surface tension of the tear film in two different times of the day, Contact Lens Anterior Eye 36 (2013) 140-145; https://doi.org/10.1016/J.CLAE.2012.12.005

30. M. Hotujac Grgurević, M. Juretić, A. Hafner, J. Lovrić and I. Pepić, Tear fluid-eye drops compatibility assessment using surface tension, Drug Dev. Ind. Pharm. 43 (2017) 275-282; https://doi.org/10.10 $80 / 03639045.2016 .1238924$ 
31. A. Ludwig and H. Reimann, Eye BT - Practical Pharmaceutics: An International Guideline for the Preparation, Care and Use of Medicinal Products, In Y. Bouwman-Boer, V. Fenton-May, \& P. Le Brun (Eds.), (pp. 163-188). Cham: Springer International Publishing; https://doi.org/10.1007/978-3319-15814-3_10

32. K. A. Fitzgerald, M. Malhotra, C. M. Curtin, F. J. O' Brien and C. M. O’ Driscoll, Life in 3D is never flat: 3D models to optimise drug delivery, J. Control. Release 215 (2015) 39-54; https://doi. org/10.1016/J.JCONREL.2015.07.020

33. M. Ruponen and A. Urtti, Undefined role of mucus as a barrier in ocular drug delivery, Eur. J. Pharm. Biopharm. 96 (2015) 442-446; https://doi.org/10.1016/J.EJPB.2015.02.032

34. I. Pepić, J. Lovrić, B. Cetina-Čižmek, S. Reichl and J. Filipović-Grčić, Toward the practical implementation of eye-related bioavailability prediction models, Drug Discov. Today 19 (2014) 31-44; https://doi.org/10.1016/J.DRUDIS.2013.08.002

35. I. Krtalić, S. Radošević, A. Hafner, M. Grassi, M. Nenadić, B. Cetina-Čižmek, J. Filipović-Grčić, I. Pepić and J. Lovrić, D-Optimal Design in the Development of Rheologically Improved In Situ Forming Ophthalmic Gel, J. Pharm. Sci. 107 (2018) 1562-1571; https://doi.org/10.1016/J. XPHS.2018.01.019

36. J. Bassi da Silva, S. B. de S. Ferreira, O. de Freitas and M. L. Bruschi, A critical review about methodologies for the analysis of mucoadhesive properties of drug delivery systems, Drug Dev. Ind. Pharm. 43 (2017) 1053-1070; https://doi.org/10.1080/03639045.2017.1294600

37. E. E. Hassan and J. M. Gallo, A Simple Rheological Method for the in Vitro Assessment of MucinPolymer Bioadhesive Bond Strength, Pharm. Res. An Off. J. Am. Assoc. Pharm. Sci. (1990); https://doi. org/10.1023/A:1015812615635 